Published in final edited form as:

Biochemistry. 2015 December 8; 54(48): 7059-7062. doi:10.1021/acs.biochem.5b00806.

\title{
Skp trimer formation is insensitive to salts in the physiological range
}

\section{Clifford W. Sandlin, Nathan R. Zaccai, and Karen G. Fleming}

T.C. Jenkins Department of Biophysics, The Johns Hopkins University, Baltimore MD 21218

Karen G. Fleming: karen.fleming@jhu.edu

\section{Abstract \\ Biogenesis of the gram-negative outer membrane involves the chaperone $\underline{\text { Seventeen }}$ Kilodalton Protein (Skp). A Skp trimer is currently thought to bind its unfolded outer membrane protein (uOMP) substrates. Using sedimentation equilibrium, we discovered that Skp is not an obligate trimer under physiological conditions and that $\mathrm{Na}^{+}, \mathrm{Cl}^{-}, \mathrm{Mg}^{2+}$, and $\mathrm{PO}_{4}{ }^{3-}$ ions are not linked to Skp trimerization. These findings suggest that electrostatics play a negligible role in Skp assembly. Our results demonstrate that Skp monomers are populated at biologically relevant concentrations, which raises the idea that kinetic formation of Skp-uOMP complexes likely involves Skp monomer assembly around its substrate. In addition, Van't Hoff analysis of Skp self-association does not support a previously proposed coupled folding and trimerization of Skp.}

\section{Graphical abstract}

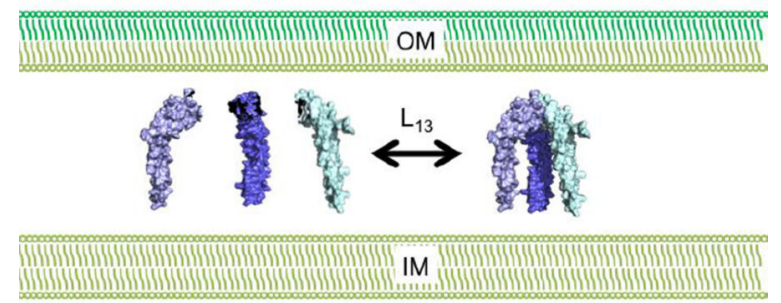

\section{Keywords}

Aggregation; Analytical Ultracentrifugation; Binding; Chaperone; Electrostatics; EnthalpyEntropy compensation; Holdase; Isotherm; Ions; Membranes; Oligomerization; Omp; Outer Membrane Biogenesis; Outer Membrane Protein; Periplasm; Sedimentation Equilibrium; Skp; Trimerization

Contact between mammalian epithelia and the outer membrane (OM) of gram-negative bacteria has an appreciable impact on symbiosis with these organisms $(1,2)$. The $\mathrm{OM}$ is

Correspondence to: Karen G. Fleming, karen. fleming@ jhu .edu.

ASSOCIATED CONTENT

Detailed experimental methods, supplemental figures S1-S7, and supplemental tables S1-S5 are found in the Supplemental Information. This material is available free of charge via the Internet at http://pubs.acs.org.

No competing financial interests have been declared. 
$67 \% \mathrm{w} / \mathrm{w}$ outer membrane proteins (OMPs) (3). OMPs are insoluble yet they must cross an aqueous periplasm to reach the OM where they fold. Transport of unfolded OMPs (uOMPs) requires protection from self-aggregation by holding chaperones like the $\underline{S}$ eventeen Kilodalton Protein (Skp) (4-6).

Skp possesses a fascinating propensity to bind unfolded proteins of diverse sequence $(7,8)$. This binding underlies the Skp function as a holding chaperone $(5,6)$, an activity accomplished by the enclosure of uOMPs within a cavity formed by a trimer of Skp monomers $(5,9,10)$. The trimer is thus accepted as the relevant species in vivo $(5,7-21)$. Evidence for this model includes binding experiments showing Skp saturates at a ratio of 3:1 Skp:uOMP (7), SANS analysis showing Skp-uOMP complexes form a 3:1 complex (22), and crystallographic analysis demonstrating that apo-Skp is trimeric $(11,13)$. Moreover, monomeric Skp has been observed only in a denatured form both on SDS-PAGE gels and by $\operatorname{NMR}(11,23)$.

As a result, consideration of a role for monomeric Skp in vivo or in vitro has been minimal. However, concentrations of Skp used in structural studies are 10-100 times higher than that of in vivo concentrations as estimated by quantitative LC/MS-MS (9-13, 18, 24, 25). This raises the question of whether Skp trimers exist at the lower concentrations more relevant to the cellular condition. To address this question, we used sedimentation equilibrium analytical ultracentrifugation (SE) to measure the mean trimerization constant for Skp, which we will refer to as $\mathrm{L}_{13}$ (supplemental methods, equations 10-11).

Because ionic phospholipid head groups are thought to interact with Skp (26), electrostatically induced dissociation of Skp trimers could potentially be a mechanism by which Skp releases its uOMP cargo at the OM. Therefore, we conducted our experiments considering previous work suggesting that electrostatics affects Skp function. Qu et al. observed a weakening of the Skp:uOMP $\mathrm{K}_{\mathrm{d}}$ in $1 \mathrm{M} \mathrm{NaCl}$ relying upon an analysis that assumed obligate Skp trimers (7). Alternatively, a weakened $\mathrm{L}_{13}$ could explain this result. More recently, it was proposed that Skp monomers are unfolded, yet fold and are stabilized by salt-bridges upon trimer formation (23). On the other hand, the Skp structure (12) possesses five Asp pairs less than $7 \AA$ apart (supplemental figure S1 and table S1), implying $\mathrm{L}_{13}$ could increase if ions screen this repulsion. Consistent with this view, De Cock et al. showed that $\mathrm{MgCl}_{2}$ protects $\mathrm{Skp}$ from proteolysis, a possible consequence of increased $\mathrm{L}_{13}$ (26). Thus, the effect of salts on $\mathrm{L}_{13}$ is unclear. Using SE, we show here that Skp is not an obligate trimer at physiological concentrations, and we demonstrate that trimerization is independent of several salts' concentrations as well as large heat capacity changes $\left(\Delta \mathrm{C}_{\mathrm{p}}\right)$ over the ranges tested.

All self-association experiments were conducted using SE. Figure 1B and supplementary figures S2A-J and Table S2 show that a monomer-trimer association model best described the data. In contrast, models including single species or other self-association schemes showed larger normalized error and systematic residuals. We therefore analyzed our data using the simpler monomer-trimer model for self-association. 
The mean trimerization constant $\left(\mathrm{L}_{13}\right)$ from three replicates for the $37{ }^{\circ} \mathrm{C}, 150 \mathrm{mM} \mathrm{NaCl}$, $\mathrm{pH} 8.0$ condition was $6.18 \times 10^{11} \mathrm{M}^{-2}$, which corresponds to $\Delta \mathrm{G}^{\circ}=-16.73 \pm 0.29 \mathrm{kcal}$ $\mathrm{mol}^{-1}$. Figure 1A shows this predicts a concentration $\left(\mathrm{C}_{1 / 2}\right)$ of $1.47 \mu \mathrm{M}$ at which half of Skp is trimeric. Using values from the literature for Skp copy numbers $(24,25)$, and an envelope volume of $0.14 \mu \mathrm{m}^{3}(29)$, the concentration of Skp in the periplasm is approximately $3.9 \mu \mathrm{M}$ under stationary phase growth in LB and $31.0 \mu \mathrm{M}$ under steady-state growth in M9+ glucose media (Figure 1A). These considerations result in monomeric fractions of $29 \%$ and $8 \%$, respectively, for the two growth conditions (Figure 1A). Thus, trimers represent only part of the Skp population in E. coli when cells are not nutritionally stressed. Under stress conditions, the fraction of trimeric Skp is predicted to increase.

Ions in either the membrane interface or periplasm could affect this fraction by serving as local triggers for complex dissociation or formation. To test this idea, we measured $\mathrm{L}_{13}$ at seven $\mathrm{NaCl}$ concentrations (50, 150, 200, 250, 350, 600, and $1000 \mathrm{mM}$ ) (Figure 2A and Table S3). We also held $\mathrm{NaCl}$ constant $(50 \mathrm{mM})$ and varied $\mathrm{MgCl}_{2}(1,2$, and $10 \mathrm{mM})$ and $\mathrm{Na}_{3}, \mathrm{PO}_{4}\left(1,10\right.$, and $100 \mathrm{mM}$ ) (Figure $2 \mathrm{~B}$ and Table $\mathrm{S} 3$ ). Figure 2 shows that $\mathrm{L}_{13}$ does not depend on salt concentration; this indicates a negligible role for electrostatics in Skp trimerization.

Burmann et al. hypothesized that salt-bridges stabilize the fold of Skp subunits (23). This model invokes linkage between salt concentration, folding and trimerization. To address whether folding occurs upon trimerization, and because protein-folding results in a $\Delta C_{p}$ observable as curvature in a Van't Hoff plot, we analyzed temperature-dependent SE data. Figures $2 \mathrm{C}$ and $\mathrm{S} 3 \mathrm{~A}$ show that a fit of $\ln \mathrm{L}_{13}$ vs. $1 / \mathrm{T}$ to the integrated Van't Hoff equation returns a $\Delta \mathrm{C}_{\mathrm{p}}=-0.62 \pm 0.11 \mathrm{kcal} \mathrm{mol}^{-1} \mathrm{~K}^{-1}$ for the $150 \mathrm{mM} \mathrm{NaCl}$ condition. To compare our experimental $\Delta \mathrm{C}_{\mathrm{p}}$ to that expected, we calculated the $\Delta \mathrm{C}_{\mathrm{p}}$ for folding $\left(\Delta \mathrm{C}_{\text {fold }}\right)$ and trimerization $\left(\Delta \mathrm{C}_{13}\right)$ (see SI Methods and Table S4) and obtained estimates of $\Delta \mathrm{C}_{\text {fold }}=-7.7$ $\pm 3.3 \mathrm{kcal} \mathrm{mol}^{-1} \mathrm{~K}^{-1}$ for the folding of three monomers and $\Delta \mathrm{C}_{13}=-0.31 \pm 0.12 \mathrm{kcal} \mathrm{mol}^{-1}$ $\mathrm{K}^{-1}$ for trimerization of three folded monomers, which sum to $\Delta \mathrm{C}_{\mathrm{p} \text {,total }}=-8.01 \pm 3.3 \mathrm{kcal}$ $\mathrm{mol}^{-1} \mathrm{~K}^{-1}$ for both reactions. Our analysis thus indicates that trimerization occurs between folded monomers. We also found that $\Delta \mathrm{C}_{\mathrm{p}}$ is largely insensitive to $\mathrm{NaCl}$ concentration (Figure S5). We cannot rule out a very small amount of partial unfolding, but overall we find no evidence for folding linked to trimerization that is stabilized by electrostatics. Instead, we observe enthalpy-entropy compensation (Figure S4).

Electrostatics has been connected with Skp since it first co-purified with LPS (30), inspiring many studies $(15-16,23)$, and with DNA, which produced the obsolete alias HLP-I (Histone-Like Protein I) (31). Even so, our results show no linkage between $\mathrm{L}_{13}$ and physiological ion activities.

Because Qu et al. observed an increased $\mathrm{K}_{\mathrm{d}}$ for uOmp binding at $1 \mathrm{M} \mathrm{NaCl}$, they suggested Coulombic forces dominate uOMP binding. We ruled out an alternative hypothesis, that $\mathrm{L}_{13}$ weakens in $1 \mathrm{M} \mathrm{NaCl}$. However, the insensitivity of Skp trimerization to $\mathrm{NaCl}$ suggests a third possibility: that uOMP aggregation is accelerated in high salt (33). Such a situation would lead to a depletion of monomeric uOMP and an increased apparent $\mathrm{K}_{\mathrm{d}}$. Moreover, 
while $\mathrm{MgCl}_{2}$ protects Skp from proteolysis (26), our results suggest this was likely not due to increased $\mathrm{L}_{13}$.

The existence of a significant population of monomeric Skp requires a reexamination of results from both in vitro and in vivo experiments. At the highest concentrations of Skp used for in vitro fluorescence binding assays $(7,32)$, more than $50 \%$ of Skp is monomeric. Yet after equilibrium is reached, a 3:1 Skp:uOmp stoichiometry is observed. This is an consequence of thermodynamic linkage: binding of uOMP substrates stabilizes the quaternary Skp:uOMP complex. Importantly, descriptions of existing $(17,19)$ and future kinetics data for complex assembly require models that account for the monomeric state. We suggest that this significant population of monomers may increase the diversity of species that could assemble around a client.

Figure 1 shows that the fraction of Skp trimers may be regulated by cellular stress (28). If trimers possess the bulk of holding activity (6), then regulation of Skp concentration regulates this activity. Such regulation of functional multimers by gene expression has been observed before $(33,34)$. Activation of Skp under stress conditions is also consistent with a model in which Skp delivers uOMPs to DegP for degradation (17). A similar model was proposed for the structurally and functionally analogous co-chaperones Prefoldin and CCT in eukaryotes (35).

In sum, our results support a view that Skp is more than a static cage. Instead, the protein experiences a dynamic monomer-trimer equilibrium and has evolved to respond to changing growth environments while remaining robust to commensurate changes in salt concentration.

\section{Supplementary Material}

Refer to Web version on PubMed Central for supplementary material.

\section{Acknowledgments}

We thank the Fleming lab members for helpful conversations.

Funding Information

Funding was provided by NSF grant MCB1412108 and NIH grants R01 GM079440 and T32 GM008403.

\section{ABBREVIATIONS}

$\begin{array}{ll}\text { AUC } & \text { Analytical Ultracentrifugation } \\ \text { CCT } & \text { Chaperonin-Containing T-Complex } \\ \text { DegP } & \text { Periplasmic Serine Endoprotease DegP } \\ \text { LC/MS } & \text { Liquid Chromatography/Mass Spectrometry } \\ \text { LPS } & \text { Lipopolysaccharide } \\ \text { OM } & \text { Outer Membrane }\end{array}$


OMP Outer Membrane Protein

SE Sedimentation Equilibrium

Skp Seventeen Kilodalton Protein

uOMP Unfolded Outer Membrane Protein

\section{REFERENCES}

1. Koli P, et al. MBio. 2011; 2

2. Malladi V, et al. Microbes Infect. 2004; 6:38-50. [PubMed: 14738892]

3. Jaroslawski S, et al. Mol Microbiol. 2009; 74:1211-1222. [PubMed: 19843216]

4. Schäfer U, Beck K, Müller M. J Biol Chem. 1999; 274:24567-24574. [PubMed: 10455120]

5. Walton TA, et al. Proc Natl Acad Sci U S A. 2009; 106:1772-1777. [PubMed: 19181847]

6. Entzminger KC, et al. Biochemistry. 2012; 51:4822-4834. [PubMed: 22650963]

7. Qu J, et al. J Mol Biol. 2007; 374:91-105. [PubMed: 17928002]

8. De D, et al. Proc Natl Acad Sci U S A. 2014; 111:1778-1783. [PubMed: 24434556]

9. Burmann BM, Wang C, Hiller S. Nat Struct Mol Biol. 2013; 20:1265-1272. [PubMed: 24077225]

10. Callon M, Burmann BM, Hiller S. Angew Chem Int Ed Engl. 2014; 53:5069-5072. [PubMed: 24700611]

11. Schlapschy M, et al. Biol Chem. 2004; 385:137-143. [PubMed: 15101556]

12. Korndörfer IP, Dommel MK, Skerra A. Nat Struct Mol Biol. 2004; 11:1015-1020. [PubMed: 15361861]

13. Walton TA, Sousa MC. Mol Cell. 2004; 15:367-374. [PubMed: 15304217]

14. Stirling PC, et al. Nat Struct Mol Biol. 2006; 13:865-870. [PubMed: 17021621]

15. Qu, J. The interactions of outer membrane proteins with the periplasmic chaperone Skp of E. coli and with LPS, in, Mathematisch- Naturwissenschaftliche Sektion. Germany: Universitat Konstanz; 2007.

16. Qu J, et al. Biochemistry. 2009; 48:4926-4936. [PubMed: 19382746]

17. Wu S, et al. Biochem J. 2011; 438:505-511. [PubMed: 21671888]

18. Burmann BM, Hiller S. Chimia (Aarau). 2012; 66:759-763. [PubMed: 23146261]

19. Lyu ZX, et al. PLoS One. 2012; 7:e46068. [PubMed: 23049938]

20. McMorran LM, et al. J Mol Biol. 2013; 425:3178-3191. [PubMed: 23796519]

21. Patel GJ, Kleinschmidt JH. Biochemistry. 2013; 52:3974-3986. [PubMed: 23641708]

22. Zaccai NR, et al. Methods in Enzymology. 2015 Under Review.

23. Burmann BMHDA, Callon M, Bond PJ, Hiller S. Biophys J. 2015; 108:1516-1526. [PubMed: 25809264]

24. Masuda T, et al. Mol Cell Proteomics. 2009; 8:2770-2777. [PubMed: 19767571]

25. Arike L, et al. J Proteomics. 2012; 75:5437-5448. [PubMed: 22771841]

26. De Cock H, et al. Eur J Biochem. 1999; 259:96-103. [PubMed: 9914480]

27. Chatton JY, Spring KR. J Membr Biol. 1995; 144:11-19. [PubMed: 7595938]

28. Tao H, et al. Journal of Bacteriology. 1999; 181:6425-6440. [PubMed: 10515934]

29. Goodsell DS. Trends Biochem Sci. 1991; 16:203-206. [PubMed: 1891800]

30. Geyer R, et al. Eur J Biochem. 1979; 98:27-38. [PubMed: 111933]

31. Holck A, Kleppe K. Gene. 1988; 67:117-124. [PubMed: 2843433]

32. Moon CP, et al. Proc Natl Acad Sci U S A. 2013; 110:4285-4290. [PubMed: 23440211]

33. Cai G-Z, et al. Biochemistry. 1990; 37:97-106.

34. Koblan KS, Ackers GK. Biochemistry. 1991; 30:7817-7821. [PubMed: 1831045]

35. Lundin VF, Leroux MR, Stirling PC. Trends Biochem Sci. 2010; 35:288-297. [PubMed: 20116259]

Biochemistry. Author manuscript; available in PMC 2016 December 08. 

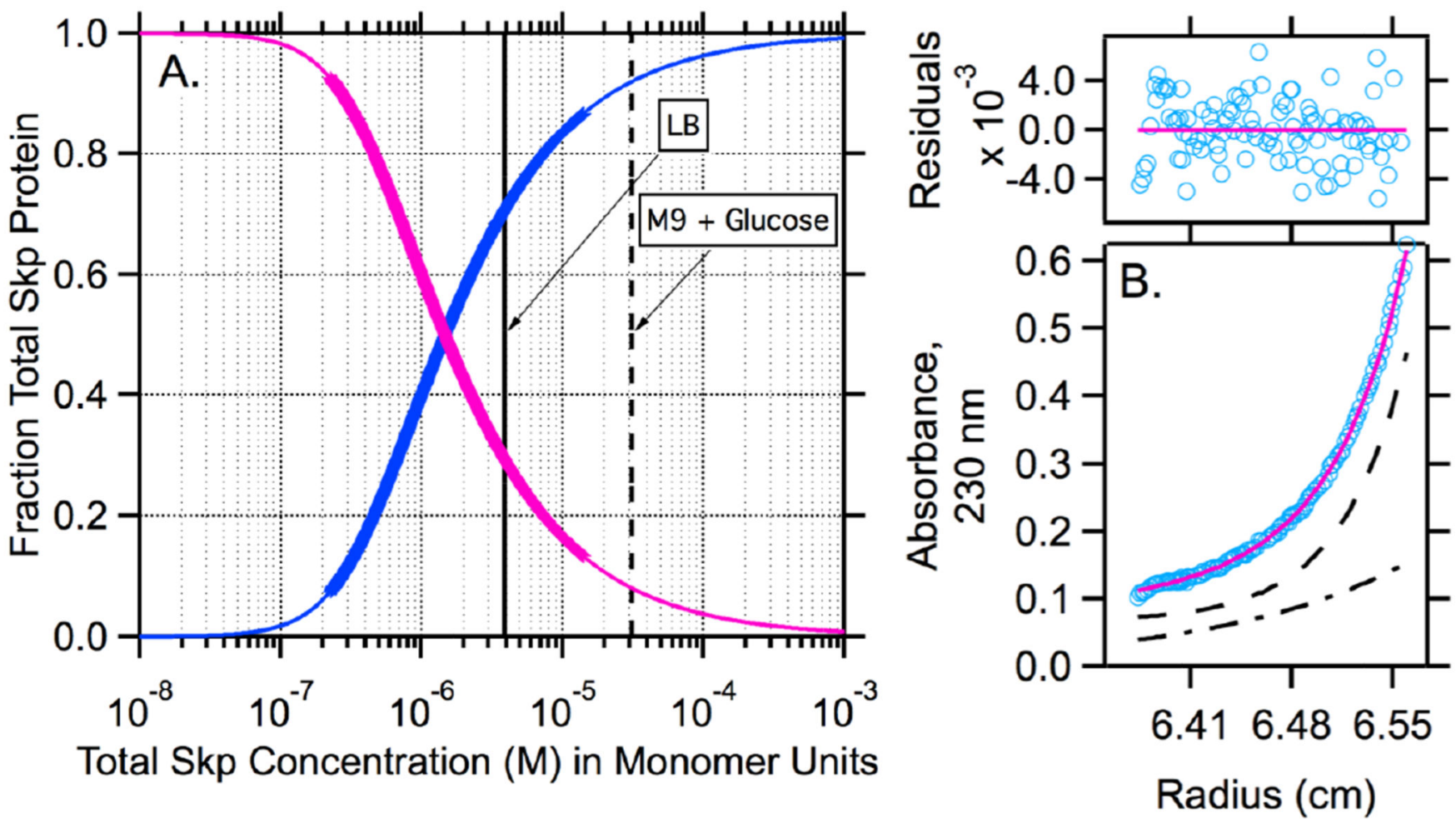

Figure 1.

A., Skp monomer populations are significant and depend on growth conditions. In blue, the fraction of total Skp in trimeric form; in magenta, the fraction of monomeric Skp. The thickened regions of the traces indicate the observable range in SE. This plot was calculated using the best-fit of $\mathrm{L}_{13}=6.18 \times 10^{11} \mathrm{M}^{-2}$ corresponding to $37^{\circ} \mathrm{C}$ and $150 \mathrm{mM} \mathrm{NaCl}$ at $\mathrm{pH}$ 8.0, similar to intestinal epithelia (27). In solid black, the estimated concentration of Skp in an Escherichia coli envelope during stationary phase growth in LB media (24); In dashed black, the Skp concentration as upregulated by sigmaE during steady-state growth in M9glucose media $(25,28)$. B., Species plot for SE data collected at $37^{\circ} \mathrm{C}$ in $150 \mathrm{mM} \mathrm{NaCl}$ and $13 \mu \mathrm{M}$ Skp at $\mathrm{pH} 8.0$ with a rotor speed of 24,500 rpm. Light blue circles, A230. Magenta line, fit to a monomer-trimer association model. Also shown are the contributing distributions of the trimeric (long dashes) and monomeric species (dots and dashes). 

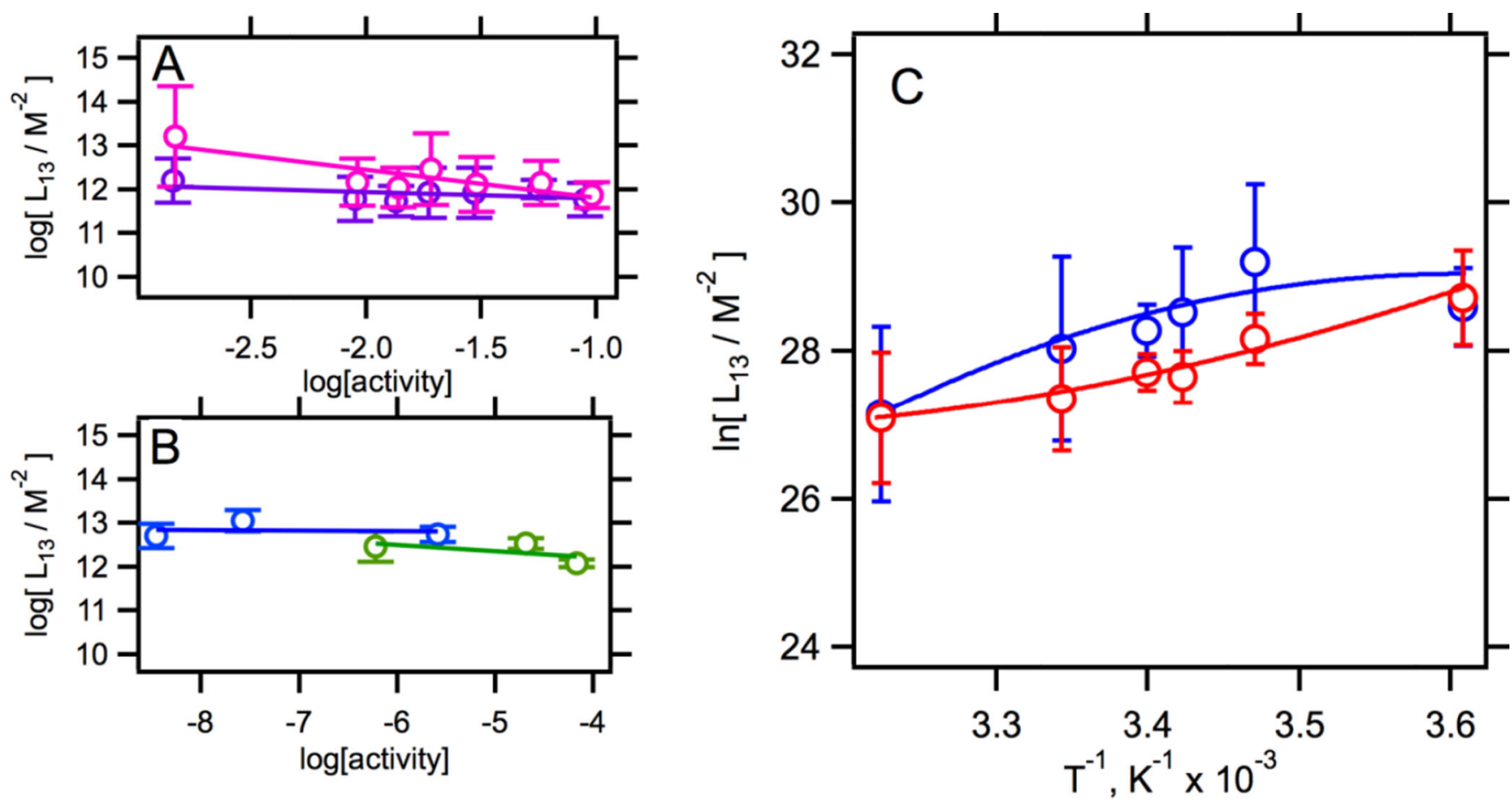

Figure 2.

Skp trimerization is not strongly affected by salt activity and displays small $\Delta \mathrm{C}_{\mathrm{p}}$. A., Linkage data for $\mathrm{NaCl}$ at $26{ }^{\circ} \mathrm{C}$ (magenta) and $37^{\circ} \mathrm{C}$ (purple) is essentially independent of $\mathrm{NaCl}$ activity. B., $\mathrm{MgCl}_{2}$ activity (blue) and $\mathrm{Na}_{3}, \mathrm{PO}_{4}$ activity (green) at $26^{\circ} \mathrm{C}$ are not linked to Skp trimerization. The relationship between activity and concentration is described in the supplementary information. C., Van't Hoff plot for Skp trimerization. Using fits to the integrated Van't Hoff equation (see also supplementary methods and Supplementary Figure 3), Skp trimerization displays a small $\Delta \mathrm{C}_{\mathrm{p}}$ at both $150 \mathrm{mM}$ (blue) and $1 \mathrm{M}[\mathrm{NaCl}]$ (red). 